\title{
Intensified job demands and job performance: does SOC strategy use make a difference?
}

\author{
Saija MAUNO ${ }^{1,2}$, Bettina KUBICEK ${ }^{3}$, Taru FELDT ${ }^{4}$ and Jaana MINKKINEN ${ }^{1 *}$ \\ ${ }^{1}$ Faculty of Social Sciences (Psychology), Tampere University, Finland \\ ${ }^{2}$ Department of Psychology, University of Jyväskylä, Finland \\ ${ }^{3}$ Institute of Psychology, University of Graz, Austria \\ ${ }^{4}$ Department of Psychology, University of Jyväskylä, Finland
}

Received April 29, 2019 and accepted October 4, 2019

Published online in J-STAGE October 11, 2019

\begin{abstract}
We examined intensified job demands (IJDs) and selecting-optimizing-compensating (SOC) strategies as predictors of job performance (task performance, organizational citizenship behavior). We also investigated SOC strategy use as a moderator in the linkages between IJDs and performance. We sampled three disparate occupational groups $(\mathrm{N}=4,582)$. We found that certain dimensions of IJDs showed significant associations with the indicators of job performance but there were also scale-based variations in these linkages, depending on the type of performance and on the sub-scale of IJDs. Specifically, some dimensions of IJDs (e.g., work intensification) related to poorer task performance whereas some other dimensions (e.g., intensified job-related learning demands) related to higher organizational citizenship behaviour. However, SOC strategy use benefitted both types of job performance. Relationships also differed between occupational groups as none of the moderator effects were consistent across the sub-samples.
\end{abstract}

Key words: Intensified job demands (IJDs), Job performance, Organizational citizenship behaviour, Selecting-optimizing-compensating strategies, Moderator effects

\section{Introduction}

\section{Background and aim}

Working life has changed dramatically in recent decades. One broad societal phenomenon behind these changes is social acceleration ${ }^{1)}$, and notably one of its facets, namely technological acceleration, which affects working life in many ways. Technological acceleration, through digitalization, artificial intelligence and robotization, is speeding up knowledge transfer and other work processes resulting in intensified, predominantly cogni-

*To whom correspondence should be addressed. E-mail: Jaana.Minkkinen@tuni.fi

(C)2020 National Institute of Occupational Safety and Health tive, job demands ${ }^{2-4)}$. In reference to this phenomenon, sociologists speak about work intensification ${ }^{2,3,5)}$ but occupational health psychologists have recently proposed a more specific concept intensified job demands (IJDs) ${ }^{4}$. Specifically, IJDs describe demand-like job characteristics which intensify and accelerate the pace of work, job- and career-related planning and decision-making and workrelated learning ${ }^{4)}$.

As new phenomena, IJDs have not received much research attention although they are of relevance in rapid technological acceleration. Few studies have ascertained their effects on employee well-being ${ }^{3-7)}$. However, no published study has examined whether IJDs also relate to employees' job performance, which is our focus here. Job performance refers to the behaviours employees engage in at work contributing to organizational goals and cov- 
ers both in-role and extra-role performance ${ }^{8,9)}$. In-role performance describes task proficiency at work (technical aspects of performance), which may be job-specific or non-specific. This type of performance is also known as task-performance. Extra-role performance refers to the more social and motivational aspects of job performance, such as facilitating peer and team performance (e.g., by helping behaviour), going the "extra mile" at work and being industrious and persistent at work ${ }^{8)}$. It is noteworthy that extra-role performance is sometimes conceptualized via organizational citizenship behaviour referring to workrelated behaviours that are not included in employees' job descriptions or not formally rewarded in organization but are nevertheless beneficial for organizations ${ }^{10)}$. As employees' job performance is crucial to organizational success $^{9,11)}$, it deserves more attention in job stress research also considering new, under-researched job demands. Accordingly, our first goal is to provide new research evidence as to whether and how IJDs relate to job performance, and, more importantly, whether such demands benefit or impair performance. We conceptualize and measure job performance via self-rated task performance and organizational citizenship behavior (OCB) defined above.

Naturally, in real life job demands cannot be avoided, and this may be especially true concerning IJDs as technological acceleration seems inevitable in working life. Consequently, it is crucial that employees have coping resources as a protection against harmful effects of job demands. Such coping resources may arise from work or from individual characteristics. One remarkable individual coping resource is action/life management strategies, here conceptualized and assessed via selectingoptimizing-compensating (SOC) strategies, referring to three intertwined personal action regulation strategies, that is, selecting-optimizing-compensating ${ }^{12,13)}$. SOC strategies operate in concert to facilitate an individual's stress adjustment and to ensure successful development over the life course. They are also relevant individual resources in the work context ${ }^{14-17)}$. Indeed, we deem SOC strategies especially valuable resources in today's working life, where employees benefit from transferable resources given that long-term employment contracts with the same organization/employer are no longer the norm. Changing working conditions would draw more attention to personal resources, which employees could more easily transfer in job changes throughout their careers. Moreover, SOC strategies have been argued to be most powerful personal resources in the presence of demands and stressors ${ }^{18,19)}$. Therefore our second goal is to investigate whether using
SOC strategies would mitigate the associations between IJDs and job performance, implying that intense SOC strategy use would help to maintain high job performance under high demands, i.e., when IJDs are high.

Empirically our study is based on three divergent occupational samples (upper white-collar workers $n=2,434$, lower white-collars workers $n=645$, blue-collar workers $n=1,505$ ), enabling us to test for the first time whether the findings concerning IJDs are generalizable across occupational groups or whether they are rather more samplespecific, thereby forming the third goal of this study.

\section{Intensified Job Demands (IJDs)_hindrance or challenge demands?}

The concept of intensified job demands (IJDs) was developed in order to account for the effects of acceleration in the world of work ${ }^{4)}$. In accordance with qualitative and quantitative accounts highlighting the increasing pressures put on workers ${ }^{6,20,21)}$, Kubicek et al. ${ }^{4)}$ propose that various job demands have intensified. Specifically, the authors distinguished four sub-dimensions of IJDs, namely work intensification, the intensification of job-related planning and decision-making demands, the intensification of career-related planning and decision-making demands, and the intensification of learning demands.

Work intensification means that work becomes more intense, with employees having to accomplish more work tasks within a working day. Kubicek et al. ${ }^{4)}$ define work intensification as a multifaceted phenomenon characterized by the need to work faster, reduce downtime, and perform different work tasks simultaneously (i.e., multitasking demands). Intensified job-related planning and decision-making demands refer to increases in decisionmaking authority that put more pressures on employees to decide which tasks to pursue and how to approach them. With diminishing career stability and mounting demands for career self-management ${ }^{22)}$ career planning and decision-making demands have intensified ${ }^{4)}$. Workers are increasingly required to maintain their employability in their current organization but also to be aware of and open to other career opportunities. Finally, intensified learning demands mean that the demands to enhance one's knowledge and skills have become more intense. Due to rapid technological advances and frequent organizational changes, workers are required to constantly update their knowledge and adjust their skills ${ }^{4}$.

It is noteworthy that work system practices necessitating a high level of involvement, which are nowadays often implemented in organizations' human resource management, 
are intensifying work, e.g., by imposing the above-defined intensified learning, planning and decision-making demands ${ }^{23)}$. Thus, IJDs, particularly intensified planning and decision-making and learning demands, have their roots not only in technological acceleration but also in today's human resource management practices, which empower employees via improved agency, self-management and autonomy but simultaneously increase their experiences of IJDs ${ }^{23,24)}$.

Research has also revealed that these four dimensions of IJDs are distinct from well-established job demands such as time pressures/workload or lack of autonomy and contribute to explaining employee health, well-being and motivation beyond these more traditional job demands ${ }^{3,4}$. Thus, IJDs expand existing measures by capturing the dynamic nature of contemporary job demands arising predominantly from technological and organizational changes.

IJDs have different associations with work-related outcomes. Whereas work intensification has been shown to be detrimental to employee well-being, health and motivation $^{3,4,6)}$, learning demands have been shown to be conducive to work-related motivation ${ }^{6,7)}$. This pattern of results suggests that some IJDs may be hindrances, whereas others may be challenges. Cavanaugh et al. (p. 68) ${ }^{25)}$ define challenge demands as "work-related demands or circumstances that, although potentially stressful, have associated potential gains for individuals"26, 27). However, hindrance demands, in turn, are not associated with such gains but "tend to constrain or interfere with an individual's work achievement" ${ }^{25)}$. Thus, hindrance demands are likely to exacerbate strain and thwart personal growth and goal attainment, whereas challenge demands, besides being energy-depleting, also stimulate motivation ${ }^{26)}$. Work intensification is associated with work-related outcomes, such as high emotional exhaustion and low work engagement ${ }^{4}$, which classify this demand as a hindrance. Moreover, if workers are asked to appraise work intensification, they assess it as a hindrance ${ }^{28)}$. As hindrances are negatively related to performance ${ }^{27)}$, we can assume that work intensification is associated with poorer job performance (task performance, OCB). No research appraising other subdimensions of IJDs has so far been presented. Nevertheless, their concurrent associations with strains and motivation suggest that planning and decision-making as well as learning demands are rather challenges ${ }^{7)}$. As challenge demands very likely boost performance ${ }^{27)}$, we can expect intensified planning and decision-making demands (jobrelated and career-related) and learning demands to be positively related to job performance (task performance, OCB).
The Selecting-Optimizing-Compensating (SOC) model from the perspective of job demands and job performance

The core elements of the SOC model are four SOC strategies (elective and loss-based selecting, optimizing, compensating), which are conceived of as significant personal resources assisting individuals' action management and agency in setting, pursuing and sustaining goals in different life domains, also at work ${ }^{12-14)}$. The SOC model was originally developed by Baltes and Baltes ${ }^{12)}$ to explain human motivation, adaptation, development and growth across the life course. Work is inherently motivational, goal-driven action, and thus job demands, including IJDs, arise from work and organizational goals, signifying that the SOC model fits occupational settings well ${ }^{14,15,29,30)}$.

The SOC model includes four specific actionmanagement strategies ${ }^{12,13)}$. Goal-setting occurs primarily via elective selection (goal setting, goal choices and goal prioritizing), and loss-based selection (giving up unachievable goals, selecting new goals, and reorganizing goal priorities). An example of elective selection is when we concentrate on the tasks assigned instead of engaging in some counterproductive behaviour at work. An example of loss-based selection at work is when we disengage ourselves from certain enjoyable job activities, e.g., meeting colleagues, because of time pressures caused by organizational goals, requiring goal prioritizing due to limited resources. As these examples show, selection in the work context is ultimately guided by organizational goals and requirements. Moreover, employees may nowadays also have conflicting work goals, e.g., multitasking requirements ${ }^{4)}$. However, to perform well and to meet organizational standards, employees are under pressure to select the most relevant goals and pursuing those.

Goal pursuing manifests best in optimizing, referring to actions and processes enabling individuals to optimize their resources (e.g., effort, time, knowledge) in order to achieve selected goals. For example, in order to cope with learning demands at work or to maintain their employability, employees may acquire new training and education. Finally, goal maintaining and successful adjustment to resource losses occur typically through compensation, describing actions that allow resource losses to be compensated. To cope with losses, people need to muster and use new internal or external resources because previously used resources may no longer be available. One typical example of resource loss is job loss when a person starts seeking compensatory resources (job seeking, training, new hobbies) in order to adjust. The original developers of the SOC model ${ }^{12,13)}$ emphasize that all four strategies 
are equally important for human adaptation and development. Indeed, SOC strategies operate in concert; using strategies flexibly across situational demands is often emphasized $^{13,31)}$. For this reason, we conceptualize SOC strategies as one global construct (average score approach) encompassing the four strategies described above ${ }^{17,30,32)}$.

Taken together, we reasoned that the SOC model with four SOC strategies is readily applicable to both job demands and job performance research. SOC strategies are personal resources that qualitatively match today's goaldriven working life packed with mental job demands, e.g., IJDs. We argue that IJDs have deep roots in organizational goals and technology-aided work processes and that employees have increasingly needed to adapt their personal goals and actions to meet proficiency-intensive organizational goals and standards. Moreover, as the SOC model is ultimately a goal theory, it is also appropriate for job performance research, where goal-related aspects are inherently relevant. Therefore, we consider that SOC strategies and job performance are also qualitatively well-matching phenomena. The "Qualitative matching principle" is one pre-condition for establishing meaningful moderator effects between job demands (IJDs), resources as moderators (SOC) and employee outcomes (job performance) (a triple-match principle) ${ }^{33)}$. We therefore regarded an orchestra SOC strategies as a meaningful moderator against IJDs in relation to job performance.

Some empirical findings support the above reasoning. However, such studies utilizing a moderator design are quite rare and have typically concerned job demands other than IJDs and also employee outcomes other than job performance, e.g., depression, working ability and workrelated fatigue. For example, Shang et al. ${ }^{34)}$ reported that SOC strategies buffered against effort-reward imbalance at work (describing overall job stress) in relation to depressive symptoms; intense SOC strategy use mitigated the stressfulness of effort-reward imbalance resulting in decreased depression. Schmitt et al. ${ }^{17)}$ for their part found that overall SOC strategy use mitigated the effects of cognitive job demands (problem-solving demands) on work-related fatigue. However, Riedel et al. ${ }^{35)}$ challenged such buffering findings as in their study SOC strategies did not ameliorate the effects of job demands on work ability. Concerning job performance as an outcome, Yeung and Fung ${ }^{36)}$ showed that SOC strategies protected against high task complexity in terms of objectively-rated job performance measured via sales volumes ${ }^{16)}$. To conclude, the empirical evidence concerning SOC strategies as buffering moderators between job demands/stressors and job performance is still scarce and more evidence should be presented, as will be done in the present study.

By contrast, there is more evidence on the direct positive relationships between SOC strategies and job performance. In a recent meta-analysis, Moghimi et al. ${ }^{15)}$ found a moderately strong relationship between SOC strategies and job performance $\left(r_{\mathrm{c}}=0.21\right)$ but the correlation coefficients varied between the studies and by the type of the outcome (e.g., self-rated vs. objective performance). As these previous findings are not entirely consistent, we examine whether SOC strategy use relates to job performance (task performance, OCB) independently of IJDs by examining the direct relationships between SOC strategy use and performance indicators.

\section{Research questions and hypotheses}

The following research questions (RQ) and hypotheses (H) are posed in this study.

$R Q$ 1. Do IJDs relate to job performance (task performance, $O C B)$ ? On the basis of the hindrance-challenge model $^{26,27)}$, we hypothesize (HI) that IJDs may relate either to poorer performance (as hindrance demands) or to better performance (as challenge demands). Specifically, we expect to find a scale-based variation in these relationships: work intensification, as a hindrance demand, is expected to relate to poorer job performance (H1a), whereas three other dimensions of IJDs (intensified job-related and career-related planning and decision-making demands, and learning demands), as challenge demands, are presumed to predict improved performance (H1b). Naturally, scale-based variation conditional upon the indicator of job performance (task performance, $\mathrm{OCB}$ ) may emerge but we propose no hypothesis on this as empirical evidence is lacking.

$R Q 2$. Does SOC strategy use relate to job performance (independently of IJDs)? As SOC strategies are notable personal resources ${ }^{12,13)}$, which have been shown to result in positive work-related outcomes ${ }^{15,17,36)}$, we hypothesize (H2) that high SOC strategy use relates to higher job performance. We propose no hypothesis on scale-based differences (concerning task performance, OCB), although we examine this possibility by analysing performance indicators independently.

$R Q$ 3. Does SOC strategy use moderate the linkages between IJDs and job performance? As SOC strategy use may be among the most powerful personal resources in demanding life circumstances ${ }^{18,19)}$, we hypothesize $(H 3)$ that SOC strategy use operates as a moderator against high IJDs in relation to job performance (task performance, OCB). Specifically, under high demands, i.e., when IJDs 
are high, high SOC users would be able to maintain a higher level of performance than would low SOC users. We propose no hypotheses on scale-based variations but we do examine this possibility.

\section{Methods}

\section{Participants and procedure}

We sampled different occupational groups in order to form a generalizable picture of IJDs in Finland and also to detect potential differences between occupational groups. Data collection, which we conducted in 2018, was performed in close collaboration with Finnish trade unions whose registered members were requested to complete an online survey. The present study was approved by institutional review board and informed consents were gained from participants.

The upper white-collar group $(n=2,434)$ consisted of teachers, whereas the lower white-collar group $(n=645)$ consisted of desk job workers (e.g., clerks, office workers) employed in the private sector. The blue-collar group $(n=1,503)$ included industrial workers (e.g., employees in the metal and food processing industries) and service workers (e.g., waiters, cashiers). The total response rate was $25.5 \%$ (56.1\% among upper white-collar workers, $12.9 \%$ among lower white-collar workers and $16.5 \%$ among blue-collar workers). A majority of blue-collar workers were women $(51 \%)$ with a mean age of 42.97 $(S D=11.86)$ yr and the most typical education among them was a qualification from a vocational school (64\%). The majority of lower white-collar workers were also women (64\%) with a mean age of $47.35(S D=10.00) \mathrm{yr}$ and the most typical education in this occupational group was a qualification from a vocational college or a university degree (59\%). The group of upper white-collar workers was heavily female-dominated (79\%) with a mean age of 49.49 $(S D=10.68)$ yr and $72 \%$ of these employees had a university degree. Occupational groups differed significantly from each other in all these background variables (detailed analyses available from the authors upon request), and we therefore deemed it important to analyse them separately regarding the research questions.

\section{Measures and correlations between key variables}

Measures and descriptive information on the sum-scales are summarized in Table 1.

We analysed four dimensions of IJDs separately as in earlier research they have been claimed to be separate factors with varying antecedents and outcomes ${ }^{4,36)}$. However,
SOC strategies (including elective selection, loss-based selection, optimization and compensation) were analysed as one average score because SOC strategies are expected to operate in concert ${ }^{13,31)}$ and a similar procedure has been used earlier in occupational settings ${ }^{17,30,32)}$. We also found that certain sub-scales of SOC had unacceptable reliability coefficients (compensation $\alpha=0.57-0.61$ ), whereas the overall SOC score (including 12 items) had good reliability across the sub-samples (Table 1).

Control variables in the regression analyses included the following basic demographic factors: sex (male/ female), age (continuous variable from low to high), education (continuous variable from $1=$ no formal vocational education ... 5=university degree), and the presence of children in the home (no/yes). These background variables were measured identically across the sub-samples and were therefore usable for purposes of comparison.

Correlations (Pearson) between all predicting variables and the outcomes are presented in greater detail in Tables 2 (task performance) and 3 (OCB). Here we present the correlations (Pearson) between the key predictors (IJDs-sub-dimensions, SOC strategy use) and between the outcomes. Sub-dimensions of IJDs were moderately highly inter-correlated in all sub-samples: among upper white-collar workers $r=0.37-0.55(p<0.001)$, lower white-collar workers $\mathrm{r}=0.42-0.53(p<0.001)$, and bluecollar workers $r=0.37-0.58(p<0.001)$. However, SOC strategy use showed only very low correlations with IJDs: among upper white-collar workers $r=0.01$ (ns) -0.12 $(p<0.001)$, lower white collar-workers $r=-0.01$ (ns) $-(-)$ $0.15(p<0.001)$, and blue-collar workers $r=0.01$ (ns) $0.12(p<0.001)$. Task performance and OCB also showed relatively low inter-correlations across the sub-samples $(r=0.21-0.26, p<0.001)$.

\section{Statistical analysis}

As we examined three very different sub-samples we first conducted a mean comparison analysis for key variables by sub-sample (upper white-collar, lower white-collar, and blue-collar workers) via ANOVAs (one-way). In these mean comparison analyses, the sub-sample served as a fixed factor, the four dimensions of IJDs, SOC, task performance and OCB as dependent variables, each of which was analysed separately. Paired comparisons in ANOVAs were conducted using post hoc Bonferroni or Games-Howell test when homogeneity of variance was violated. We set a $p$-level of $\leq 0.001$ due to the large data $(n=3,297)$. The results of these analyses will be reported as descriptive findings ( $M$ and $S D$ across sub-samples are shown in Table 1). 
Table 1. Summary table of measures and descriptive figures $(M, S D)$ across sub-samples $(1,2,3)$ concerning seven sub-scales

\begin{tabular}{|c|c|c|c|c|c|c|c|c|c|}
\hline Scale & & oefficic & & & $\mathrm{M} / \mathrm{SD}$ & & Scale- & No. of & Reference and example items \\
\hline Sample & 1 & 2 & 3 & 1 & 2 & 3 & & & \\
\hline WI & 0.90 & 0.89 & 0.88 & $3.85 / 1.02$ & $3.68 / 1.00$ & $3.36 / 1.12$ & $1-5 / \mathrm{L}^{\mathrm{a}}$ & 5 & $\begin{array}{l}\text { "In the last five years ever more work has to be completed by } \\
\text { fewer and fewer employees"4) }\end{array}$ \\
\hline IJP & 0.85 & 0.84 & 0.86 & $3.53 / 0.92$ & $3.68 / 0.86$ & $3.15 / 0.98$ & $1-5 / \mathrm{L}$ & 5 & $\begin{array}{l}\text { "In the last five years one increasingly has to check independently } \\
\text { whether the work goals have been reached" } 4 \text { ) }\end{array}$ \\
\hline ICP & 0.76 & 0.78 & 0.76 & $3.42 / 0.95$ & $3.52 / 0.89$ & $3.04 / 0.99$ & $1-5 / \mathrm{L}$ & 3 & $\begin{array}{l}\text { "In the last five years one is increasingly required to maintain } \\
\text { one's attractiveness for the job market, e.g., through advanced } \\
\text { education, networking" } 4 \text { ) }\end{array}$ \\
\hline LD & 0.93 & 0.94 & 0.93 & $4.11 / 0.82$ & $3.79 / 0.89$ & $3.09 / 1.02$ & $1-5 / \mathrm{L}$ & 6 & $\begin{array}{l}\text { "In the last five years one has to update one's knowledge level } \\
\text { more frequently" } 4 \text { ) }\end{array}$ \\
\hline SOC & 0.75 & 0.76 & 0.79 & $3.30 / 0.48$ & $3.37 / 0.47$ & $3.44 / 0.50$ & $1-7 / \mathrm{L}$ & 12 & $\begin{array}{l}\text { "I concentrate all my energy on a "few things" (selecting); } \\
\text { "When I can't do something important at work the way I did } \\
\text { before, I look for a new goal" (loss-based selection); "At work, I } \\
\text { keep working on what I have planned until I succeed" (optimiz- } \\
\text { ing), "When something at work isn't working as well as it used } \\
\text { to, I ask others for advice" (compensating) }\end{array}$ \\
\hline $\mathrm{TP}$ & 0.79 & 0.82 & 0.79 & $3.57 / 0.68$ & $3.55 / 0.75$ & $3.61 / 0.77$ & $1-5 / \mathrm{F}^{\mathrm{b}}$ & 4 & "I was able to plan my work so that I finished it on time" \\
\hline OCB & 0.76 & 0.74 & 0.76 & $3.74 / 0.54$ & $3.55 / 0.55$ & $3.50 / 0.60$ & $1-5 / F$ & 8 & $\begin{array}{l}\text { "Willingly give your time to help others who have work-related } \\
\text { problems" }\end{array}$ \\
\hline
\end{tabular}

1: upper white-collar workers; 2: lower white-collar workers; 3: blue-collar workers. *Higher score indicates higher amount/level of the given construct.

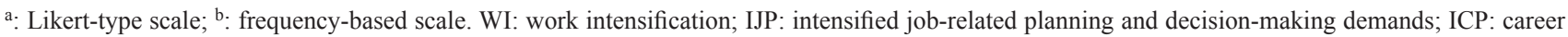
planning and decision-making demands; LD: intensified learning demands; SOC: selecting-optimizing-compensating strategies; TP: task performance; OCB: organizational citizenship behavior.

The hypotheses (H1-H3) were tested by performing hierarchical moderated regression analyses with interaction terms. Regression analyses were conducted separately for three divergent sub-samples in order to examine the generalizability of the direct (IJDs, SOC) and moderator (IJDs $\times$ SOC interaction) effects across sub-samples. Noteworthy is also that this is a first study on IJDs (as measured multi-dimensionally) where divergent samples were used in predicting performance. For this reason, we deemed important to analyse whether the explanation rates of IJDs concerning performance differ according to the subsamples. This would mean that IJDs (or some of those) are stronger predictors of performance in certain occupational groups. This same concerns also SOC variable as a predictor of performance, as earlier studies have not generally been multi-sample studies.

Specifically, we computed different regression models for the main (IJDs, SOC) and moderator (IJDs $\times$ SOC) effects. We first examined the main effects of IJDs and SOC on job performance (task performance, $\mathrm{OCB}$ as dependent variables) in own models (testing $\mathrm{H} 1, \mathrm{H} 2$ ). In these regression models (method Enter), background factors (sex, age, education and parenting status) were entered in the first step, followed by the SOC variable in the second step.
Then the dimensions of IJDs (altogether four variables) were entered into the models at separate steps (i.e., including four steps as there were four IJDs among the variables) in order to compare their relative importance and explanation power in relation to job performance. The dimension of work intensification was entered in the last step because we defined this dimension of intensification as a hindrance demand (see H1a, H1b), and in this regard we also thought that it would be more detrimental (negative) job demand compared to the other (challenge-type) IJDs. Thus, the dimension of work intensification was expected to show the strongest (negative) effect on performance and was then entered to the model in the final step of regression analysis.

Next we estimated the moderator models to investigate whether SOC strategy use moderated the effects between IJDs and job performance (testing H3). SOC was always among these interaction terms, and having the same variable in multiple interaction terms typically causes multicollinearity and unreliable regression coefficients. Hence, to avoid multi-collinearity, each IJD variable and its corresponding interaction term with SOC, was analysed separately (altogether four interaction terms). In interpreting the interaction effects we used two specific criteria: (1) the interaction effect had to be consistent with the correspond- 


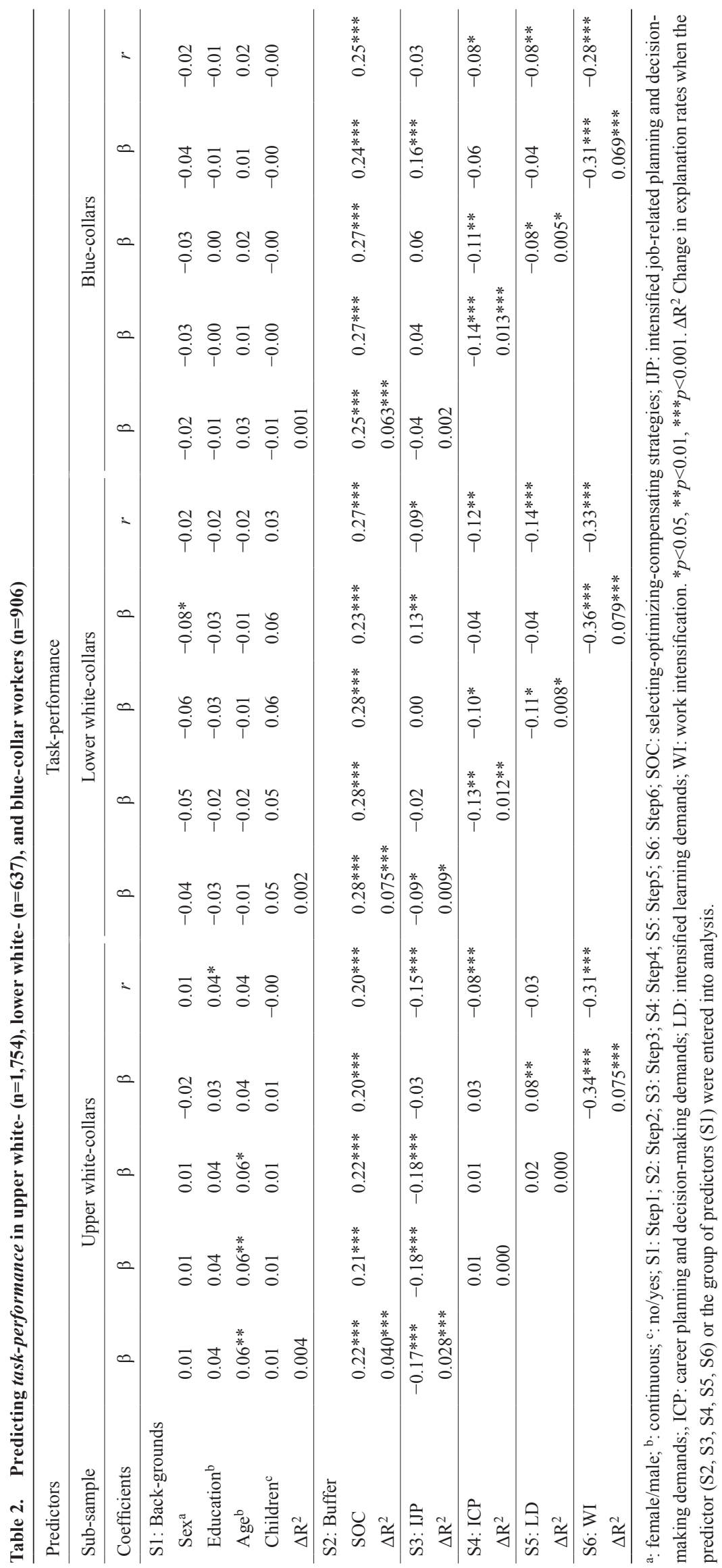


ing correlation coefficient and the correlation coefficient had to be significant; (2) the change in an explanation rate $\left(\mathrm{R}^{2}\right)$ after entering the interaction term had to be significant and explain $>0.5 \%$ of the variance of the dependent variable. Interaction effects meeting these criteria were then graphically inspected based on the parameter values of beta-coefficients, confidence intervals and standard deviations ${ }^{38)}$. It is noteworthy that we used a stricter level of significance in the upper white-collar worker sample $\left({ }^{*} p<0.01\right)$ due to large sample size $(n=2,434)$, whereas in the two other sub-samples we used a conventional significance level $\left({ }^{*} p<0.05\right)$.

\section{Results}

Descriptive results: mean comparisons by sub-samples for the key concepts

Below we report differences by sub-samples based on $F$ - and $p$-values. Means and standard deviations in each of the three sub-samples are presented in Table 1. ANOVAs showed that the sub-samples differed in all other constructs except task performance ( $F=1.56$, df [2, 3296], $p=0.210$ ). Upper and lower white-collar workers reported more work intensification than did blue-collar workers $(F=64.79, d f[2$, 3297], $p<0.001$ ), whereas the white-collar groups did not differ from each other (post hoc Games-Howell for paired comparisons). Lower white-collar and upper-white-collar workers also reported more intensified job-related planning and decision-making demands than did blue-collar workers ( $F=73.63, d f$ [2, 3297], $p<0.001)$, and all groups differed significantly from each other (Games-Howell) in this job demand. Similarly, the white-collar groups reported more intensified career-related planning and decisionmaking demands than did the blue-collar group ( $F=61.84$, $d f$ [2, 3297], $p<0.001)$ but the white-collar groups did not differ from each other (Games-Howell). Finally, intensified learning demands were also most prevalent among upper white-collar workers, followed by lower white-collar workers and blue-collar workers $(F=387.99, d f[2,3297]$, $p<0.001)$ and all sub-samples differed significantly from each other (Games-Howell). To sum up, IJDs were overall more common in white-collar than in blue-collar work.

We also found that the sub-samples differed in SOC strategies $(F=24.39, d f[2,3297] p<0.001)$ and OCB $(F=63.58, d f[2,3297], p<0.001)$. The blue-collar workers used SOC strategies more often than did the upper whitecollar workers, whereas other groups did not differ from each other (Bonferroni). OCB, in turn, was most common among upper white-collar workers but the lower white- collar group did not differ from the blue-collar workers (Games-Howell).

\section{Results of regression analyses for the main effect models} in three sub-samples

Here we report only the findings derived from the last step of the regression analysis as these are the most robust findings taking into account the power of antecedents when all variables are included in the model (see Step 6; after all four dimensions of IJDs were entered into the regression analysis). Furthermore, we only report those findings which are consistent with the corresponding correlation coefficient.

Concerning task performance, Table 2 shows that SOC strategy use explained higher task performance in each subsample and its explanatory rates varied between 4 and $8 \%$ depending on the sub-sample. Of the dimensions of IJDs, only work intensification showed a consistent effect on task performance across sub-samples: the higher work intensification the lower was task performance. Work intensification explained $7-8 \%$ of the variance of task performance. It is noteworthy that none of the other dimensions of IJDs were significant predictors of task performance after entering the dimension of work intensification into the model in the final step (see $\beta$-coefficients in the last column across sub-samples). Some effects at Step 6 were furthermore inconsistent with the respective correlation coefficient (i.e., concerning IJP in lower white-collar workers and bluecollar workers and LD in upper white-collar workers, see $\beta$-and $r$-coefficients in the last column across sub-samples). Altogether, these findings show that the relative importance of work intensification was stronger than the other dimensions of IJDs in explaining task performance.

Table 3 shows the results of the regression analysis in explaining organizational citizenship behaviour (OCB) across sub-samples. Again, we report the findings derived from the last step of the regression analysis after all variables had been entered into the model (see Step 6; after all four dimensions of IJDs had been entered to the regression analysis). We found that SOC strategy use explained higher OCB in each sub-sample and its explanatory rates varied between 4 and 5\% depending on the sub-sample. None of the dimensions of IJDs related consistently to OCB at Step 6 (see $\beta$-coefficients in the last column across sub-samples). However, we found that intensified learning demands were related to higher OCB among upper whitecollar and blue-collar employees (the effects were also consistent with the respective correlation coefficients). Among blue-collar workers, intensified planning- and 


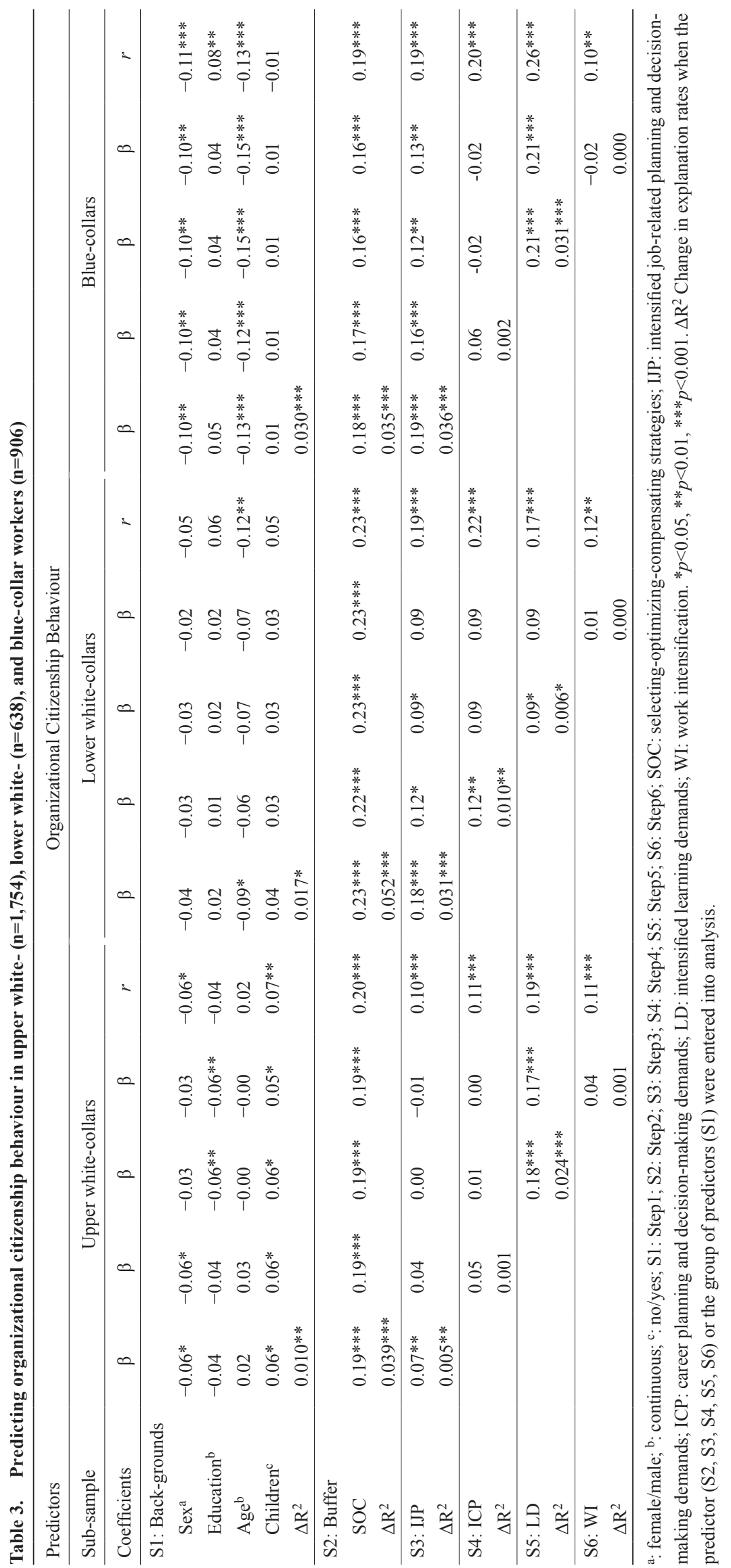


decision-making demands also related to higher OCB after entering all variables into the regression equation. Overall, the explanatory power of IJDs was weaker concerning OCB $(0.5-4 \%)$ as an indicator of performance compared to task performance (7-8\%), which was most strongly explained by work intensification.

Results of the regression analysis for the moderation models in three sub-samples

We found only a few significant interpretable interaction effects and none of these were consistent across the sub-samples. Furthermore, some of these interaction effects were inconsistent with the respective correlation coefficient and were therefore not interpreted further (see criteria for interpreting effects in Statistical analysis). All interpretable interaction effects emerged in the lower white-collar worker sample and three of those were clear moderating effects and are reported next. Figure 1 reveals an interaction effect of work intensification and SOC on TP $(\beta=0.12, p<0.01)$ by showing that SOC strategy use buffered to some extent against work intensification. According to the simple slope analysis, among the high SOC users (1 $S D$ above mean) the association between work intensification and task performance was lower $(\beta=-0.21$, $p<0.001)$ than among the low SOC users $(1 S D$ below mean; $\beta=-0.44, p<0.001)$. However, the main effect of work intensification is also evident in Fig. 1: the higher work intensification, the lower was task performance.

Another buffering effect, again among lower white-collar workers, concerned task performance and emerged for the intensified learning demands $(\beta=0.09, p<0.05)$. As can be seen in Fig. 2, SOC strategy use buffered against intensified learning demands. According to the simple slope analysis, among the high SOC users (1 SD above mean) the association between intensified learning demands and task performance was not significant ( $\beta=-0.06, p=0.227$ ) while among the low SOC users (1 SD below mean) the association between intensified learning demands and task performance was stronger $(\beta=-0.24, p<0.001)$ than among those whose use of SOC strategies was average $(\beta=-0.15, p<0.001)$.

The third moderation effect, again among lower whitecollar workers, concerned OCB and was found for the intensified career related planning and decision-making demands $(\beta=0.10, p<0.01)$. Figure 3 illustrates this interaction effect and reveals that SOC strategy use strengthened the positive association between intensified career demands and OCB. According to the simple slope analysis, among the high SOC users (1 SD above mean) the association between intensified career demands and OCB was

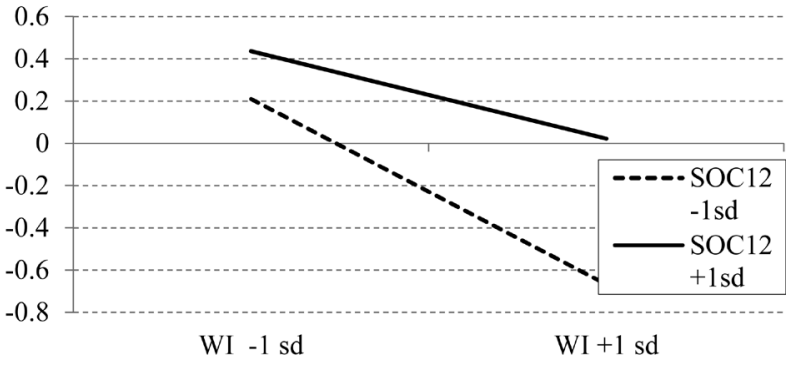

Fig. 1. WI*SOC interaction effect on TP among lower white-collar workers; $\boldsymbol{\beta}=0.12 *$.

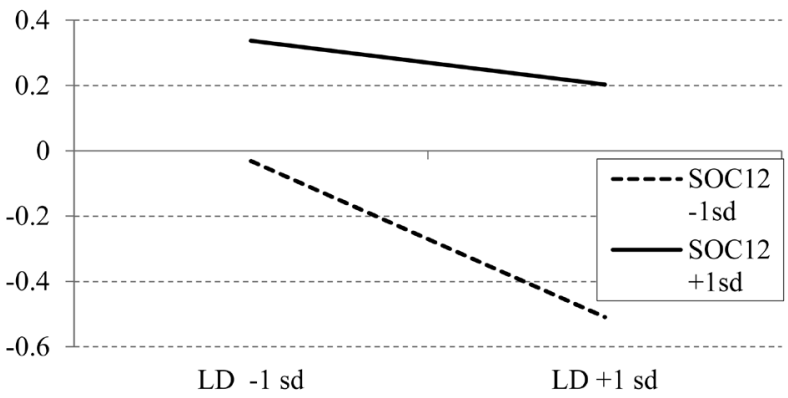

Fig. 2. LD*SOC interaction effect on TP among lower white-collar workers; $\beta=0.09 *$.

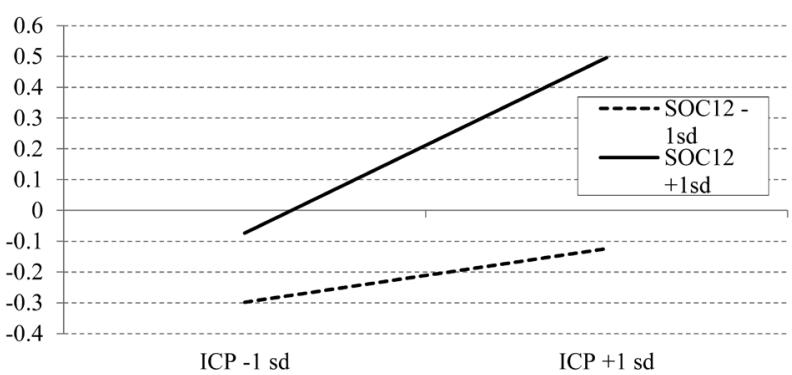

Fig. 3. ICP*SOC interaction effect on $\mathrm{OCB}$ among lower whitecollars workers; $\boldsymbol{\beta}=\mathbf{0 . 1 0} *$.

stronger $(\beta=0.29, p<0.001)$ than among those whose use of SOC strategies was average $(\beta=0.19, p<0.001)$ while among the low SOC users (1 SD below mean) the association between intensified career demands and OCB was not significant $(\beta=0.09, p=0.107)$.

\section{Discussion}

The present study examined intensified job demands (IJDs) and selecting-optimizing-compensating (SOC) strategies as predictors of job performance (task performance and OCB). Furthermore, we explored whether SOC strategy use 
would function as a moderator in the linkages between IJDs and job performance. We sampled three disparate occupational groups in order to examine the generalizability of our findings but to also explore potential differences between occupational groups. We found that certain dimensions of IJDs showed significant associations with the indicators of job performance but there were also scale-based variations in these linkages, depending particularly on the type of performance but also on the sub-scale of IJDs. Moreover, many relationships also differed between occupational groups. Indeed, none of the moderator effects were consistent across the occupational groups. We next discuss our main findings in relation to the hypotheses $(\mathrm{H} 1-\mathrm{H} 3)$ focusing also on differences between the outcomes (task performance, OCB) and occupational groups.

\section{The dimension of work intensification was most important}

The first hypotheses (H1a, H1b) were only partially supported and the findings differed by type of job performance. Only work intensification acted as a hindrance demand for all employees when task performance served as an indicator of performance; the higher work intensification the lower was task performance. Entering the dimension of work intensification into the model suppressed the effects of other dimensions of IJDs, although their correlations with performance were often significant. This signals a stronger relative importance of work intensification on (task) performance compared to the other dimensions of IJDs. This result is also consistent with H1a and previous findings showing that work intensification is a hindrance demand associated with negative outcomes ${ }^{4,6,28)}$. It should, however, be recalled that work intensification did not predict OCB, which was the second indicator of job performance here, and in this respect HIla was only partially supported.

In addition, we hypothesized that intensified job- and career-related demands and intensified learning demands would act as challenge demands with positive performancerelated outcomes $(\mathrm{H} 1 \mathrm{~b})^{26,27)}$. However, this hypothesis did not gain much support in our data. As noted above, these three dimensions of IJDs were not related to task performance (inconsistent with $\mathrm{H} 1 \mathrm{~b}$ ) after analysing the effect of work intensification suppressing the effects of other dimensions of IJDs. We found, however, that higher intensified learning demands explained higher OCB among upper white-collar and blue-collar workers, lending some support to $\mathrm{H} 1 \mathrm{~b}$, according to which learning demands are challenge demands with beneficial motivational and performance outcomes $^{25-27)}$. Other effects between IJDs and OCB were likewise either marginal or sample-specific. For example, we found that higher intensified job-related planning- and decision-making demands related to higher OCB among lower white- and blue-collar workers (explanation rate 3-4\%) in line with HIlb, but this effect lost power when all four variables of IJDs were analysed simultaneously.

To conclude, what we found here is that the effects of IJDs were different for different indicators of job performance. Furthermore, the effects found were generally relatively low (except for work intensification) in robust statistical analyses, even though almost all four IJDs correlated significantly with the indicators of job performance across sub-samples (particularly concerning OCB). It maybe that certain employee characteristics explain the results obtained. A recent study showed that IJDs were reported more by those employees who had proactive personality ${ }^{37)}$. This could be one confounding factor explaining, e.g., the positive relationships between certain IJDs and OCB as the latter describes employees' proactive and initiative behaviours (e.g., helping co-workers, doing extra-role tasks) in organizations ${ }^{9,10)}$.

Sample-specific findings may relate to employees' different internalized expectations, implying that their psychological contract regarding IJDs may vary across occupations. These expectations were not studied here. Thus, employees in different jobs and positions may expect different amounts of job demands (e.g., planning- and decision-making demands, learning demands) as a part of their psychological contract. Such differences, stemming from the psychological contract, may then have implications for the relationship between IJDs and job performance.

It should be recalled that neither sample-based nor measure-based (regarding the outcomes) differences between IJDs and the outcomes were anticipated but we explored these as large data sets allowed such analyses. As a result, we found that not all linkages were generalizable across the sub-samples. However, SOC strategy use was an exception and will be discussed next.

\section{Selecting-Optimizing-Compensating (SOC) strategies were useful but not strong stress buffers}

The second hypothesis (H2) was fully supported as higher SOC strategy use predicted better job performance (both task performance and OCB) across the occupational groups. The result is also consistent with earlier findings showing that SOC strategies lead to various positive outcomes in occupational contexts ${ }^{15,17,30,37)}$. Theoretically, our results also support the SOC model proposing that SOC strategies operate in concert ("more is better"), and that their flexible use tends to produce good out- 
comes $^{12-14)}$. Thus, selecting, optimizing and compensating are beneficial action regulation strategies also in work contexts across different occupations.

The third hypothesis (H3) was only marginally supported as we found only three clear moderator effects for SOC strategy use in the association between IJDs and job performance. All interpretable interaction effects emerged in the lower white-collar sample, and two of those were clear buffering effects, in which we were particularly interested. Specifically, we found that SOC strategy use buffered against work intensification: among high SOC users we found a smaller association between greater work intensification and poorer task performance than among low SOC users. Another buffering effect of SOC strategy use emerged for intensified learning demands: among high SOC users intensified learning demands did not associate with task performance at all, whereas among low SOC users the association between intensified learning demands and task performance was stronger comparing to those who used SOC strategies on average. Altogether, our findings show that high SOC users fared better in terms of job performance than did low SOC users in a high stress situation, that is, when IJDs (work intensification, intensified learning demands) were high.

These results are also consistent with some earlier findings reporting that SOC strategies buffer against other types of job demands/stressors ${ }^{16,17,36)}$. Nevertheless, we have no unequivocal explanation for why such buffering effects were only seen among lower white-collar workers. One explanation is that their work contexts, e.g., organizational demands, were different from those of the other occupational groups studied. It may also be that technological acceleration (e.g., digitalization) has lasted longer in private services (where the lower white-collar employees worked) than in other fields where this technological revolution is currently ongoing. Thus employees in private services may have already developed protective resources, e.g., SOC strategies take-up, to cope with IJDs, the roots of which lie in technological acceleration ${ }^{1,5,37)}$. Whatever the reasons behind these sample-specific findings, it signifies that employees who work in private services, e.g., as clerks, accountants, and office workers would benefit from SOC strategy use if they encounter work intensification and intensified learning demands at work.

We also encourage scholars to investigate more SOC strategies as moderators/buffers between different job demands and performance indicators. Both SOC strategies and job performance concern goal-related cognitions and behaviour $^{8,9,12)}$ hence their inter-relationship is inherently interesting. Moreover, the ongoing technological acceleration in working life gives rise to new, predominantly cognitive, job demands ${ }^{4-6,37)}$, the effects of which deserve more attention in relation to job performance and SOC strategies.

\section{Limitations and future directions for research}

The present study has few noteworthy limitations. First, data sets were collected via self-reports, which may cause common-method variance bias. Assessing job performance via self-reports in particular has apparent weaknesses and future studies on IJDs should include non-self-report assessment of job performance. It is also noteworthy that the key variables, i.e., IJDs and SOC strategy use, were evaluated somewhat differently in our study: the items measuring IJDs refer to more "overall perceptions" concerning a respondent's job demands ${ }^{4}$, whereas the items measuring SOC refer to a respondent's personal perceptions concerning his/her SOC strategy use $\mathrm{e}^{13,15,30,31)}$. Absence of equivalence in these assessment scales may have diminished the power of the interaction effects (IJDs $\times$ SOC) found here.

Second, the study was cross-sectional and inherently limited as regards causal conclusions. We based our design on job stress models, where job demands (IJDs) are perceived to be antecedents for employee outcomes ${ }^{26,27)}$. Future longitudinal studies should examine causality between IJDs and job performance. Such longitudinal studies would also enable reliable testing of mediator models, e.g., whether SOC strategies mediate (rather than moderate) the effects between IJDs and the outcomes. The moderator effects were weak in the present study and therefore mediator effects would deserve more attention in future longitudinal studies.

Third, we analysed SOC strategy use as an average score but examining its sub-dimensions would produce more detailed information on the role of specific SOC strategies as regards job demands and employee outcomes. However, our design was justified according to the developers of SOC model, who emphasize that SOC subdimensions operate in concert ${ }^{12,13)}$. Furthermore, certain SOC-dimensions had unacceptable scale reliability and therefore an average SOC score was used.

Fourth, even though we utilized large and divergent samples, the response rate was low except for the upper white-collar group. Low response rates in online surveys are nowadays unfortunately more a rule than an excep$\operatorname{tion}^{39)}$. A related point is that we did not have detailed information about the respondents' occupations (not included in the survey), which would have been useful in interpreting the findings.

Finally, we want to emphasize that many findings were 
sample- and scale-specific. Due to such contradictory findings, future studies should explore more different indicators of job performance in relation to IJDs, also paying attention to individual differences (plus other confounding factors) possibly involved in these relationships. For example, personality factors were not measured in our study. One future avenue of research could also to be to investigate the interaction or combined effects of IJDs on job performance as this was beyond the scope of the work at hand.

\section{Implications}

Concerning implications, we base our suggestions on those effects, which were generalizable across occupational groups and would therefore benefit different occupational groups. First of all, we found that intensified pace of work and multitasking requirements (work intensification) explained poorer task performance across the occupational groups. Accordingly, organizations should try to reduce work intensification and multitasking demands. If working days or tasks assigned are extremely intense, employees should be able to recover after work and during work, e.g., by detaching themselves psychologically from work as this improves their work ability in the long run ${ }^{40)}$. Energy management strategies, e.g., private and physical microbreaks $^{41)}$, would also be needed during intense work tasks/ periods as our brains need restoration and unwinding. Allowing at least five minutes' break between mentally demanding work tasks and trying to avoid multitasking could be recommended ${ }^{42)}$.

We also showed that SOC strategy use was related to improved job performance (in-role and extra-role) across the occupational groups. Therefore, employees' SOC strategies should be enhanced in organizations using appropriate interventions and job redesign. For example, combining job crafting/redesign and SOC training interventions would yield good outcomes as they both involve goal-relevant behaviour and thinking ${ }^{43}$. Goal-setting, goal prioritizing, goal monitoring and goal resetting can be learned across the life span, concerning also one's career span ${ }^{12-14)}$.

\section{Acknowledgement}

The study was supported by the Academy of Finland (grant numbers 308334 and 308 306).

\section{References}

1) Rosa H (2003) Social acceleration: ethical and political consequences of a desynchronized high-speed society.
Constellations 10, 3-33. [CrossRef]

2) Green F (2004) Work intensification, discretion, and the decline in well-being at work. East Econ J 30, 615-25.

3) Franke F (2015) Is work intensification extra stress? J Pers Psychol 14, 17-27. [CrossRef]

4) Kubicek B, Paškvan M, Korunka C (2015) Development and validation of an instrument for assessing job demands arising from accelerated change: the intensification of job demands scale (IDS). Eur J Work Organ Psychol 24, 898-913. [CrossRef]

5) Chesley N (2014) Information and communication technology use, work intensification and employee strain and stress. Work Employ Soc 28, 589-610. [CrossRef]

6) Boxall P, Macky K (2014) High-involvement work processes, work intensification, and employee well-being. Work Employ Soc 28, 963-84. [CrossRef]

7) Korunka C, Kubicek B, Paškvan M, Ulferts H (2015) Changes in work intensification and intensified learning: challenge or hindrance demands? J Manag Psychol 30, 786-800. [CrossRef]

8) Campbell JP (1990) Modeling the performance prediction problem in industrial and organizational psychology. In: Handbook of industrial and organizational psychology, 2nd ed., vol. 1, Dunnette MD and Hough LM (Eds.), 687-732, Consulting Psychologist Press, Palo Alto.

9) Jex SM, Britt TW (2014) Organizational psychology: A scientific-practitioner approach, 3rd Ed., 133-177, John Wiley \& Sons, New Jersey.

10) Organ DW (1994) Organizational citizenship behavior and the good soldier. In: Personnel selection and classification, Rumsey MG, Walker CB and Harris JH (Eds.), 53-67, Erlbaum, Hillsdale.

11) Podsakoff NP, Whiting SW, Podsakoff PM, Blume BD (2009) Individual- and organizational-level consequences of organizational citizenship behaviors: a meta-analysis. J Appl Psychol 94, 122-41. [Medline] [CrossRef]

12) Baltes PB, Baltes MM (1990) Psychological perspectives on successful aging: the model of selective optimization with compensation. In: Successful aging: perspectives from the behavioral sciences, Baltes PB and Baltes MM (Eds.), 1-34, Cambridge University Press, New York.

13) Freund AM, Baltes PB (2000) The orchestration of selection, optimization, and compensation: an actionoriented conceptualization of a theory of developmental regulation. In: Control of human behavior, mental processes, and consciousness, Perrig WJ and Grob A (Eds.), 35-58, Lawrence Erlbaum, Mahwah.

14) Baltes PB, Dickson MW (2001) Using life-span models in industrial-organizational psychology: the theory of selective optimization with compensation. Appl Dev Sci 5, 51-62. [CrossRef]

15) Moghimi D, Zacher H, Scheibe S, van Yperen NW (2017) The selection, optimization, and compensation model in the work context: a systematic review and meta-analysis of two decades of research. J Organ Behav 38, 247-75. [CrossRef] 
16) Müller A, Weigl M (2017) SOC strategies and organizational citizenship behaviors toward the benefits of co-workers: a multi-source study. Front Psychol 8, 1740. [Medline] [CrossRef]

17) Schmitt A, Zacher H, Frese M (2012) The buffering effect of selection, optimization, and compensation strategy use on the relationship between problem solving demands and occupational well-being: a daily diary study. J Occup Health Psychol 17, 139-49. [Medline] [CrossRef]

18) Robinson SA, Rickenbach EH, Lachman ME (2016) Selfregulatory strategies in daily life: selection, optimization, and compensation and everyday memory problems. Int $\mathrm{J}$ Behav Dev 40, 126-36. [Medline] [CrossRef]

19) Young LM, Baltes BB, Pratt AK (2007) Using selection, optimization, and compensation to reduce job/family stressors: effective when it matters. J Bus Psychol 21, 511-39. [CrossRef]

20) Burchell B, Ladipo D, Wilkinson F (Eds.) (2005) Job insecurity and work intensification, Routledge.

21) Hassard J, Morris J (2017) Corporate restructuring, work intensification and perceptual politics: exploring the ambiguity of managerial job insecurity. Econ Ind Democracy. [CrossRef].

22) King $Z$ (2004) Career self-management. Its nature, causes and consequences. J Vocat Behav 65, 112-33. [CrossRef]

23) Oppenauer V, Van De Voorde K (2018) Exploring the relationships between high involvement work system practices, work demands and emotional exhaustion: a multi-level study. Int J Hum Resour Manage 29, 311-37. [CrossRef]

24) Jansen JM, Patel PC, Messersmith JG (2013) HighPerformance work systems and job control: consequences for anxiety, role overload, and turnover intentions. J Manage 39, 1699-724.

25) Cavanaugh MA, Boswell WR, Roehling MV, Boudreau JW (2000) An empirical examination of self-reported work stress among U.S. managers. J Appl Psychol 85, 65-74. [Medline] [CrossRef]

26) Crawford ER, Lepine JA, Rich BL (2010) Linking job demands and resources to employee engagement and burnout: a theoretical extension and meta-analytic test. J Appl Psychol 95, 834-48. [Medline] [CrossRef]

27) LePine JA, Podsakoff NP, LePine MA (2005) A metaanalytic test of the challenge stressor-hindrance stressor framework: an explanation for inconsistent relationships among stressors and performance. Acad Manage J 48, 764-75. [CrossRef]

28) Paškvan M, Kubicek B, Prem R, Korunka C (2014) Cognitive appraisal of work intensification. Int J Stress Manag 23, 124-46. [CrossRef]

29) Zacher H, Chan F, Bakker A, Demerouti E (2015) Selection, optimization, and compensation strategies: interactive effects on daily work engagement. J Vocat Behav 87, 101-7. [CrossRef]

30) Zacher H, Frese M (2011) Maintaining a focus on opportunities at work: the interplay between age, job complexity, and the use of selection, optimization, and compensation strategies. J Organ Behav 32, 291-318. [CrossRef]

31) Freund AM (2008) Successful aging as management of resources: the role of selection, optimization, and compensation. Res Hum Dev 5, 94-106. [CrossRef]

32) Weigl M, Müller A, Hornung S, Leidenberger M, Heiden B (2014) Job resources and work engagement: the contributing role of selection, optimization, and compensation strategies at work. J Labour Mark Res 47, 299-312. [CrossRef]

33) De Jonge J, Demerouti E, Dormann C (2014) Current theoretical perspectives in work psychology. In: An introduction to contemporary work psychology, Peeters MCW, de Jonge J and Taris TW (Eds.), 89-115, WileyBlackwell, Chichester.

34) Shang L, Riedel N, Loerbroks A, Müller A, Wege N, Angerer P, Li J (2015) The association between effortreward imbalance and depressive symptoms is modified by selection, optimization, and compensation strategy. J Occup Environ Med 57, 1222-7. [Medline] [CrossRef]

35) Riedel N, Müller A, Ebener M (2015) Applying strategies of selection, optimization, and compensation to maintain work ability - a psychosocial resource complementing the job demand-control model? Results from the representative lidA cohort study on work, age, and health in Germany $\mathrm{J}$ Occup Environ Med 57, 552-61. [Medline] [CrossRef]

36) Yeung DY, Fung HH (2009) Aging and work: how do SOC strategies contribute to job performance across adulthood? Psychol Aging 24, 927-40. [Medline] [CrossRef]

37) Mauno S, Kubicek B, Minkkinen J, Korunka C (2019) Antecedents of intensified job demands: evidence from Austria. Employee Relat 41, 694-707. [CrossRef]

38) Aiken LS, West SG, Reno RR (1991) Multiple Regression: testing and Interpreting Interactions, Sage, Thousand Oaks.

39) Baruch Y, Holtom B (2008) Survey response rate levels and trends in organizational research. Hum Relat 61, 1139-60. [CrossRef]

40) Sonnentag S, Fritz C (2015) Recovery from job stress: the stressor-detachment model as an integrative framework. J Organ Behav 36, S72-103. [CrossRef]

41) Kinnunen U, Feldt T, de Bloom J, Korpela K (2015) Patterns of daily energy management at work: relations to employee well-being and job characteristics. Int Arch Occup Environ Health 88, 1077-86. [Medline] [CrossRef]

42) Sianoja M, Kinnunen U, de Bloom J, Korpela K, Geurts S (2016) Recovery during lunch breaks: testing long-term relations with energy levels at work. Scand J Work Organ Psychol 1, 7. [CrossRef]

43) Müller A, Heiden B, Herbig B, Poppe F, Angerer P (2016) Improving well-being at work: a randomized controlled intervention based on selection, optimization, and compensation. J Occup Health Psychol 21, 169-81. [Medline] [CrossRef] 